\title{
O COTIDIANO DA EDUCAÇÃO INFANTIL E A PRESENÇA DA EDUCAÇÃO FÍSICA NA POÉTICA DE SER CRIÁNÇA ${ }^{1}$
}

\author{
Victor José Machado de Oliveira \\ Universidade Federal do Espírito Santo, Vitória, Espírito Santo, Brasil \\ David Gomes Martins \\ Faculdade Católica Salesiana do Espírito Santo, Vitória, Espírito Santo, Brasil \\ Nilton Poletto Pimentel \\ Faculdade Católica Salesiana do Espírito Santo, Vitória, Espírito Santo, Brasil
}

\begin{abstract}
Resumo
Este estudo é fruto das atividades desenvolvidas no Estágio Curricular Supervisionado e tem por objetivo apresentar as experiências obtidas durante o percurso do mesmo discutindo a presença da educação física no cotidiano da educação infantil num Centro Municipal de Educação Infantil no município de Cariacica/ES. A metodologia utilizada pautou-se na natureza qualitativa configurando-se na aplicação de nove intervenções a uma turma de vinte crianças com idade de quatro anos. A discussão teórico-metodológica foi traçada mediante o caráter heurístico de investigação e esteve baseada no conceito do cotidiano percebendo as crianças enquanto poéticas, produtoras de conhecimento e sujeitos ativos no processo ensino-aprendizagem.
\end{abstract}

Palavras-chave: Educação Infantil. Educação Física e Treinamento. Intervenção Precoce (Educação).

\section{Caminhos percorridos no estágio curricular supervisionado: um pequeno histórico que marcou nossa trajetória}

E ste texto tem por objetivo apresentar a experiência do Estágio Curricular Supervisionado $(\mathrm{ECS})^{2}$ desenvolvida por nós acadêmicos da Faculdade Católica Salesiana do Espírito Santo. O primeiro momento do ECS consistiu na análise de conjuntura educacional e observação co-participativa de aulas de educação física em um Centro

1-Uma versão inicial deste texto foi apresentada no XII Congresso Espírito-Santense de Educação Física/IV Congresso Sudeste de Ciências do Esporte realizado no CEFD/UFES - Vitória/ES, 2012. O presente trabalho não contou com apoio financeiro de nenhuma natureza para sua realização. Não houve conflitos de interesse para a realização do presente estudo.

2-O ECS foi desenvolvido durante os semestres de 2010/2 e 2011/1.

Pensar a Prática, Goiânia, v. 16, n. 1, p. 1-319, jan./mar. 2013 
Municipal de Educação Infantil (CMEI) do município de Vitória/ES. $\mathrm{O}$ segundo momento foi marcado pela mudança $\mathrm{a}^{3}$ para um CMEI em Cariacica/ES, onde realizamos nove intervenções.

É importante salientar que a educação física não está inserida no rol dos CMEI's da rede do sistema educacional do município de Cariacica. Entretanto este primeiro contato foi uma boa iniciativa, pois a comunidade do CMEI achou profícua nossa presença ali desenvolvendo intervenções a partir do trabalho realizado com a educação física - diretora, professoras, pedagoga, coordenadora, etc. Percebemos isso devido à demanda que se achou instituída, proporcionar intervenções significativas que atendessem também o desenvolvimento integral das crianças.

A instituição a qual estivemos inseridos durante as intervenções do estágio é caracterizada pela excelência do serviço prestado a comunidade de Itaquari, Cariacica/ES, desde sua constituição há dois anos. O CMEI fica próximo a Secretaria Municipal de Educação, suas instalações são novas e todas planejadas segundo os sujeitos que ali são atendidos - as crianças de 1 a 5 anos. Percebemos que isso remete a visão de uma instituição modelo que recebe periodicamente visitas dos supervisores da secretaria de educação. O espaço também é partilhado pela comunidade, que sempre desenvolve projetos em suas dependências.

A turma a qual realizamos as intervenções é constituída por vinte crianças - treze meninas e sete meninos. As crianças tem em média 4 anos de idade. Quanto a origem geográfica, grande parte provém da comunidade do entorno, sendo outras ainda de bairros mais distantes e até mesmo outros municípios.

Os períodos do estágio perpassaram a construção sistemática de um plano de intervenção. A ausência da imagem da/do professora/professor de educação física no segundo período do estágio de certa forma tirou um momento importante onde poderíamos realizar trocas de experiências e apreender mais sobre a prática pedagógica a ser desenvolvida na educação infantil. Entretanto essa situação sugeriu uma construção mais comprometida por nossa parte, de forma que atendesse as crianças e assim também pudesse propiciar discussões acerca

3-Essa mudança ocorreu mediante a instalação da greve dos professores no município de Vitória que logo se espalhou pelos municípios vizinhos.

Pensar a Prática, Goiânia, v. 16, n. 1, p. 1-319, jan./mar. 2013 
da implementação da educação física na rede municipal de educação infantil de Cariacica.

\section{Infância, educação infantil e educação física: demarcando nossa proposta de intervenção}

Nem sempre houve uma preocupação com a educação infantil, pois o próprio reconhecimento da infância ocorreu de forma tardia em nossa sociedade (SAYÃO, 2002). Com relação ao Brasil, as últimas décadas desvendam uma maior preocupação com esse nível de ensino. Esta começa a ganhar espaço de preocupação quando é reconhecida na Constituição Federal (CF) de 1988. Outros documentos oficiais vieram após a $\mathrm{CF}$ de 88 regulamentando a infância em suas particularidades. Entre elas citamos o Estatuto da Criança e do Adolescente (ECA), a Lei de Diretrizes e Bases Nacionais (LDBN/96) e o Referencial Curricular Nacional para educação infantil (RCNEI).

A CF de 1988 assegura a educação infantil como dever do Estado e direito da criança. Porém esse direito deve estar atrelado ao comprometimento com os padrões de qualidade, os aspectos político-pedagógicos, tanto quanto os aspectos físico-estruturais, "no sentido de garantir o bem-estar das crianças" (OLIVEIRA, 2008, p. 47). Confirmando esse pensamento o RCNEI aponta que "a estes princípios cabe acrescentar que as crianças têm direito, antes de tudo, de viver experiências prazerosas nas instituições" (BRASIL, 1998a, p. 14). Ainda segundo o RCNEI a promoção da qualidade envolve políticas públicas, orçamentárias, de recursos humanos e físicos, tanto quanto às propostas educacionais compatíveis às faixas etárias atendidas (BRASIL, 1998a).

A qualidade comprometida com a educação das crianças busca uma aprendizagem significativa. Esta tem forte relação com os espaços físico/estruturais e os materiais utilizados nesse momento, uma vez que, é na interação também com o objeto que as crianças constroem mecanismos mais gerais de funcionamento e da apropriação do conhecimento (adaptação, organização, assimilação e acomodação). Entretanto, alerta Andrade Filho (2007), ao ir além da interação com o objeto, faz-se necessário afirmar a criança enquanto sujeito histórico e inserido numa cultura, tendo assim o direito a um tratamento pedagógico específico e que atenda suas necessidades. 
Neste ponto a brincadeira - enquanto instrumento didático-pedagógico - é um momento significativo de aprendizagem para a criança, pois é nela que a criança instrumentaliza sua investigação e construção do conhecimento - de si mesma e do mundo que a cerca. Como aponta o RCNEI "os brinquedos constituem-se, entre outros, em objetos privilegiados da educação das crianças" (BRASIL, 1998a, p. 71). Então ter contato com uma gama de brinquedos ${ }^{4}$ possibilita à criança dar significados as suas relações interpessoais, e corrobora na construção sócio-afetivo-emocional, tanto quanto no processo educacional.

Quanto à educação física, esta se configura como momento importante na educação básica. Ela deve ter autonomia e atuação como qualquer outra disciplina na escola, e ainda mais, deve ser uma disciplina da e para a escola sem se tornar auxiliar em detrimento de outras. A educação infantil apresenta-se com uma particularidade entre os níveis de ensino da educação básica, sendo que neste segmento não há disciplinas. Entretanto a educação física tem uma participação importante neste processo educacional, pois é ela que proporciona as crianças a sistematização dos brinquedos, as brincadeiras e os jogos, participando ativamente no desenvolvimento integral destas. Ou seja, é imprescindível sua presença neste tempo-espaço, uma vez que tem muito a contribuir a partir da cultura corporal.

Entendendo a presença da educação física na educação infantil realizamos um trabalho em consonância com nossa escolha teórico-metodológica, visando as crianças como poéticas ${ }^{5}$, produtoras de conhecimento e participantes ativas na construção das atividades propostas, e não meros "bonecos" que possamos inferir o que irão fazer ou não. De forma integrada e concomitante através das experiências do cotidiano abordamos a infância como possibilidades. Assim elegemos nos jogos, brincadeiras, brincadeiras cantadas e contação de história momentos de construção de conhecimento pensando as crianças como seres completos, totais e indivisíveis.

4-Entenda brinquedo aqui como aqueles que fazem parte de uma cultura e se expressam através da oralidade sendo transmitidos desta forma de geração para geração. Brinquedos como cantigas de roda, parlendas, o pião, o bodoque, a amarelinha e jogos de pedrinhas (CASCUDO apud BERNARDES, 2006).

5-Poética: do grego poien que significa criar, inventar, gerar. Essa expressão utilizada por Certeau (1994) abarca o intentamento de detectar nas poéticas as "fabricações", aquilo que os consumidores - aqui as crianças - fazem com os produtos.

Pensar a Prática, Goiânia, v. 16, n. 1, p. 1-319, jan./mar. 2013 
Durante as atividades desenvolvidas inquietações foram surgindo fomentando três problemáticas a serem pensadas e refletidas por nós: a) Qual é a pragmática da educação física na educação infantil? b) Como e o que aplicar num tempo-espaço que não contempla no seu projeto de ensino a educação física? c) Como realizar uma intervenção que atendesse as crianças enquanto alteridades/singularidades articulando os preceitos propostos nos documentos oficiais de cuidados e ensino?

Buscando responder essas problemáticas elegemos como objetivo central da intervenção proposta construir um leque de experiências significativas que atendessem a realidade das crianças desenvolvendo seus aspectos motores, cognitivos, sociais, afetivos e estabelecendo interlocuções (diálogos) com a poética de ser criança, inserindo-as no contexto da cultura corporal. Adiante procuraremos estabelecer esse diálogo a partir das experiências obtidas em nossas intervenções engendradas no cotidiano das crianças e na relação dos usos e consumos que essas fazem durante o brincar.

\section{O cotidiano das crianças na educação infantil e o uso/consumo dos brinquedos/brincadeiras}

As experiências do estágio são constituídas neste texto através da dimensão heurística uma vez que se buscou o entendimento de um fenômeno estabelecido no cotidiano da educação infantil, principalmente quanto à presença da educação física. Desta forma, perceber os usos e consumos que as crianças fazem dos objetos sociais (CERTEAU, 1994) possibilita alçar fundamentos de aporte teóricos que poderão vir a serem objetos de pesquisa futuramente.

O primeiro fator que percebemos encontra-se no marco característico e singular das crianças da turma de nossas intervenções, uma vez que estas não tiveram contato com a educação física anteriormente. Inicialmente elas não entenderam qual seria a proposta de nossa intervenção, mas com o desenvolver-se destas foram constituindo uma visão - através de uma rotina flexível - do que é a educação física. Isso se deu devido ao fato de que as crianças não são seres cristalizados pela cultura à qual estão inseridas, elas são o aqui-agora e ainda bem que assim o seja. É neste momento que observamo-las em suas alteridades, na esfera empírica. Ocorre que "a criança se doa às possibili- 
dades do presente" (SILVA; SANT'AGOSTINO; KUNZ, 2007, p. 7), ou seja, ela não se preocupa com o que ela é ou tem.

Outro fator que atentamos durante a estada no CMEI foram as linguagens "não verbais". Os silêncios das crianças muito nos falaram durante as intervenções, tanto quanto os sorrisos, as caretas e mais variadas expressões faciais e corporais. A criança tem muito a falar em seus silêncios, e sobre isso bem nos alerta Rocha apud Silva \& Baumel $(2009$, p. 2)

[...] e lembremos que, quando o outro é uma criança, a linguagem oral não é central e nem única, ela é fortemente acompanhada de outras expressões corporais, gestuais e faciais. Isso já nos indica alguns dos problemas metodológicos envolvidos na pesquisa com crianças.

Nessas manifestações acerca da presença poética da criança na educação infantil - e do lugar que esta ocupa - podemos tecer algumas reflexões dos achados durante nossas intervenções. Neste sentido nos apoiamos no estudo de Certeau (1994) acerca da invenção do cotidiano para compreender esse fenômeno. Segundo o autor

Dessas características o enunciado fornece um modelo, mas elas vão se encontrar na relação que outras práticas (caminhar, morar, etc.) mantêm com sistemas não linguísticos. [...] Pode-se tentar aplicar o seu modelo à muitas operações não linguísticas, tomando como hipótese que todos esses usos dependem do consumo (CERTEAU, 1994, p. 96-97).

O enunciado apresenta quatro momentos: a) uma efetuação; b) uma apropriação; c) um contrato (intermédio um interlocutor); d) um presente (organização de uma temporalidade). A partir desse entendimento podemos visionar nosso objeto de estudo em suas particularidades, ou seja, a criança brincando no cotidiano a partir dos usos e consumos que esta realiza no contato com os brinquedos e brincadeiras.

Esse objeto social que perpassa o cotidiano infantil - a brincadeira - é marcado pela historicidade cultural e que por si compõe a cultura infantil. Quando propomos o "resgate" dos brinquedos e brincadeiras populares em nossa intervenção o fizemos pensando na contribuição 
que a educação física tem a proporcionar para as crianças neste nível de ensino. Assim assegurando sistematicamente a perpetuação da cultura infantil (BERNARDES, 2006) que muito se tem perdido com o advento dos avanços tecnológicos que tem tirado das crianças o prazer de brincar através dos brinquedos populares.

Ao brincar a criança nem sempre brinca sozinha. Percebe-se isso na problemática do enunciado apontado por Certeau (1994), quando essa faz uso das brincadeiras, esta institui um contrato relacional com um interlocutor (real ou fíctício). Então desde as brincadeiras coletivas, individuais, cantadas, tanto no faz de conta através da contação de histórias a criança estabelece um diálogo com o outro e por seguinte uma apropriação do conhecimento - de brincar - elegendo uma temporalidade a partir do agora (presente) criando um antes e um depois. Exemplo disso em nossas intervenções foi a construção dos brinquedos populares. O presente elegido na construção marcou para as crianças um antes - onde não sabiam o que era o brinquedo popular - e o depois - onde brincavam com o que antes não conheciam. Essa é a capacidade da criança de ser o aqui-agora.

Quando do uso prático da construção de brinquedos percebemos durante as intervenções que a criança "assina aí sua existência de autor" (CERTEAU, 1994, p. 94). Essa é a poética em que se apresentam quando assumem seu espaço dentro do processo de educação. Balizando essas considerações podemos analisar como possivelmente uma bricolagem $^{6}$, ou seja, as maneiras de colocar sobre os objetos formas singulares de criação de significados e sentidos. Provavelmente está aí uma das manipulações secundárias apontada por Certeau (1994), quando em nossas intervenções as crianças retornam o brinquedo com novas formas de brincar.

Outro momento que marcou nossas intervenções será o que a princípio chamaremos de "dispersões e debandadas". Não referenciamos esse momento de forma pejorativa, mas como um instante durante as atividades em que uma criança ou um determinado grupo de crianças não querem brincar, ou querem brincar de outras formas. Acabam por si despendendo-se da brincadeira inicial remontando-a de outras for-

6-Bricolagem é comentada por Certeau (1994) em sua obra A Invenção do Cotidiano. Entendemos ela como sendo o conjunto de disposições que constituem nossa capacidade de acoplar/integrar com vistas a organização provisória de uma permanente criação do fazer.

Pensar a Prática, Goiânia, v. 16, n. 1, p. 1-319, jan./mar. 2013 
mas. Seguido desse momento muitas das "dispersões e debandadas" acabavam por atrapalhar o seguimento de algumas atividades.

Seguindo as orientações do RCNEI "o estabelecimento de um clima de segurança, confiança, afetividade, incentivo, elogios e limites colocados de forma sincera, clara e afetiva dão o tom de qualidade da interação entre adultos e crianças" (BRASIL, 1998b). Eleger a partir do diálogo contratos acerca das possibilidades dentro do espaço das intervenções mostrou-se profícuo no segmento das atividades. Com o passar do tempo as "dispersões e debandas" foram sendo percebidas como constituintes da própria apropriação das relações no brincar, sendo essas uma forma de produção secundária (CERTEAU, 1994). Conforme aponta Certeau (1994, p. 40)

A presença e a circulação de uma representação (ensinada como código da promoção sócio econômica por pregadores, por educadores ou por vulgarizadores) não indicam de modo algum o que ela é para seus usuários. É ainda necessário analisar a sua manipulação pelos praticantes que não a fabricam. Só então é que se pode apreciar a diferença ou a semelhança entre a produção da imagem e a produção secundária que se esconde nos processos de sua utilização.

As "dispersões e debandadas" retornam nesse momento como uma antidisciplina repleta de microrresistências que fundam microliberdades. Em nossas intervenções percebemos que as crianças não são passivas à dominação adultocêntrica, pois quando manipulam o brinquedo dão novos significados ao mesmo. E a representação da brincadeira para a criança não é a mesma que a nossa, e ainda bem que assim o seja. Entendemos que nesse momento é necessário compreender a produção secundária da brincadeira quando ocorre uma dispersão e/ou debandada. Dessa forma acabamos com a visão bancária verticalizada bem lembrada por Freire (1996), do professor que domina o conhecimento depositando-o na cabeça dos seus alunos.

Um fato que demarca o cotidiano da educação infantil é a constituição da rotina. Esta amplamente marcada pela construção/ampliação do repertório de signos por parte das crianças e adultos. Com respeito a esse fato bem nos alerta Sayão (2002, p. 50) que 
a vivencia em espaços coletivos com outras crianças e adultos possibilita aos meninos e meninas, e mesmo aos adultos, a ampliação de seus conhecimentos em inúmeras dimensões como ética, estética, corporal, sensível, oral, escrita, artística, rítmica, entre outras, que se expressam nos muitos momentos em que as crianças brincam sozinhas ou em grupos.

Nesse momento o movimento aparece na rotina vinculada às linguagens enriquecendo as possibilidades de comunicação e expressão, apresentando-se como um potente veículo de socialização. Isso foi percebido nas intervenções uma vez que tecendo mediações acerca do brincar as crianças puderam ampliar seus repertórios de brincadeiras e conhecimentos. Pudemos perceber uma construção pessoal e coletiva do conhecimento nesse momento em que as crianças ao brincarem entre si apropriavam-se dos conhecimentos nas mais variadas dimensões citadas acima por Sayão (2002). Concordando com esse pensamento o RCNEI afirma que "ao brincar, jogar, imitar e criar ritmos e movimentos, as crianças também se apropriam do repertório da cultura corporal na qual estão inseridas" (BRASIL, 1998c, p. 15). Neste momento a educação física tem com o que contribuir neste tempo-espaço realizando um trabalho interventivo de construção/ampliação do conhecimento acerca da cultura corporal.

\section{O espaço da "não aula"”: prolegômenos}

Para uma compreensão desse pensamento levantado durante nossa estada no campo de estágio, foi necessário inquirir vestígios de como é compreendido a estrutura de organização didática do tempo que perpassa o cotidiano da educação infantil. O uso dos espaços, as "interrupções" das atividades e a constituição da rotina foram elementos pinçados de nossa prática durante o estágio que possibilitou a percepção da instauração do espaço da "não aula".

Segundo o RCNEI

7-Quando expressamos o termo "não-aula" não queremos dizer que este seja condicionado a "a-aula" - ausência da aula -, mas sim a constituição de um tempo-espaço que protagonize a criança enquanto poética, organizando o tempo didático segundo seus anseios e necessidades.

Pensar a Prática, Goiânia, v. 16, n. 1, p. 1-319, jan./mar. 2013 
A rotina representa, também, a estrutura sobre a qual será organizado o tempo didático, ou seja, o tempo de trabalho educativo realizado com as crianças. A rotina deve envolver os cuidados, as brincadeiras e as situações de aprendizagens orientadas. [...] Estas estruturas didáticas contêm múltiplas estratégias que são organizadas em função das intenções educativas expressas no projeto educativo, constituindo-se em um instrumento para o planejamento do professor. Podem ser agrupadas em três grandes modalidades de organização do tempo. São elas: atividades permanentes, seqüência de atividades e projetos de trabalho (BRASIL, 1998a, p. 54-55).

As atividades permanentes estão ligadas "às necessidades básicas de cuidados, aprendizagem e de prazer para as crianças, cujos conteúdos necessitam de uma constância" (BRASIL, 1998a, p. 55). As brincadeiras, rodas de história e conversação, oficinas de desenho, cuidados com o corpo e alimentação são exemplos de atividades permanentes. Enquanto isso a sequência de atividades são apresentadas como aquelas planejadas e orientadas numa intenção específica de aprendizagem. Essas devem ser inseridas mediante um contexto específico conformando-se em desafios e situações problemas em que as crianças possam desenvolver-se. Os projetos de trabalho referem-se ao conjunto de "atividades que trabalham com conhecimentos específicos construídos a partir de um dos eixos de trabalho que se organizam ao redor de um problema para resolver ou um produto final que se quer obter" (BRASIL, 1998a, p. 57). Apresenta uma característica específica, a imprevisibilidade uma vez que depende do objetivo, das etapas do processo e interesse das crianças.

Essas três modalidades não se apresentam em momentos estanques e dissociados. Ao contrário, práticas recorrentes da organização da rotina na/da educação infantil são vinculadas entre si numa relação intrínseca de interdependência. Isso foi perceptível uma vez que toda nossa intervenção foi pautada a partir dessas modalidades de organização do tempo.

Fundamentando nosso primeiro pensamento do que chamamos de "não-aula" encontramos na crítica de Certeau (1994) a Foucault, contribuições acerca de um novo olhar das instituições da sociedade disciplinar para além da vigilância. A obra de Foucault "privilegia o aparelho produtor (da disciplina), ainda que, na 'educação', ela ponha 
em evidência o sistema de uma 'repressão' e mostre como, por trás dos bastidores, tecnologias mudas determinam ou curto-circuitam as encenações institucionais" (CERTEAU, 1994, p. 41). Percebemos na instituição escolar condutas repressoras que nem tanto divergem as práticas dos sujeitos que nela estão inseridos, uma vez que estes se apoiam nas microresistências não sendo totalmente passivos a diretividade disciplinar desses mecanismos.

Fato da instituição disciplinar na educação infantil é a escolarização precoce imposta através do molde educacional hodierno propedêutico as fases posteriores, ou seja, a criança deve ser preparada desde cedo para a escola, que deve prepará-la para a faculdade e cursos técnicos, e por fim para o mercado de trabalho.

Marcos característicos foram sendo percebidos em nossa passagem pelo CMEI acerca da escolarização da educação infantil. As conformações estruturais e arquitetônicas como, por exemplo, a presença da sala de aula e a configuração da aula como tempo-espaço de ensinoaprendizagem. Isso foi percebido quando perguntamos as crianças no último dia de intervenção: o que é a educação física? A resposta que circulou foi que a educação física é uma "aula". Resposta que inquietou-nos uma vez que nosso trabalho foi realizado buscando desconstruir essa visão pautada no modelo escolarizante. Concernente a esse pensamento Sayão (2002, p. 47) aponta que "a Educação Física quando presente no currículo da Educação Infantil não pode pautar-se por um modelo 'escolarizante', que objetive antecipar [...] a preparação das crianças no ensino fundamental".

A nosso ver a constituição da aula na educação infantil é uma forma de tentativa de instauração de uma vigilância panóptica ${ }^{8}$ das crianças, que acaba cercando as possibilidades desta de desenvolver-se integralmente. Por outro lado Certeau (1994, p. 41) amplia essa visão ao afirmar que

Se é verdade que por toda a parte se estende e se precisa a rede da "vigilância", mais urgente ainda é descobrir como é que uma sociedade inteira não se reduz a ela: que procedimentos populares (também 'minúsculos' e cotidianos) jogam com os mecanismos da disciplina e não se conformam com ela a não ser para alterá-los; enfim, que "maneiras de fazer" formam a contrapar-

8-Para mais informações ver Foucault (2010).

Pensar a Prática, Goiânia, v. 16, n. 1, p. 1-319, jan./mar. 2013 
tida, do lado dos consumidores (ou "dominados"?), dos processos mudos que organizam a ordenação sócio-política.

Neste momento durante nossas intervenções percebeu-se que as crianças não se reduzem ao espaço da aula uma vez que elas inventam mil maneiras de fazer o cotidiano. Jogando com os mecanismos de disciplina através de ações "minúsculas" como, por exemplo, quando ao final da intervenção ainda continuam brincando, aprendendo e desenvolvendo-se, as crianças se afirmam enquanto consumidoras do brincar para além do momento do que numa situação escolarizada, remeteria ao espaço da aula.

Analisando a relação uso/consumo no espaço da "não-aula" apreciamos a percepção denotadora privilegiada para se encontrar as formalidades próprias ás práticas recorrentes realizadas pelas crianças. Gilbert Ryle citado por Certeau (1994, p. 95) "[...] servindo-se de uma distinção saussuriana entre a 'língua' (um sistema) e a 'palavra' (um ato), comparava a primeira a um capital e a segunda às operações que ele permite de um lado um estoque, do outro, negócios e usos". Quanto ao consumo concordamos com Certeau (1994) que enquanto a produção fornece um capital, os usuários adquirem o direito de efetuar operações mesmo não sendo seus proprietários.

Assim como no campo da "língua" a brincadeira enquanto possível campo de entendimento das relações que a criança institui em seu cotidiano apresenta essa distinção entre a "brincadeira/brinquedo" (um sistema) e o "brincar" (um ato). As artes de fazer das crianças em nossas intervenções mostraram que mesmo não sendo proprietárias das brincadeiras, brinquedos e da própria intervenção - adquiriram o direito de efetuar suas próprias operações sobre os mesmos. Esse é o espaço da "não-aula" que percebemos e objetivamos neste momento explicitar segundo os achados em nossa passagem pelo estágio.

\section{Considerações finais}

O ECS conformou-se num momento de aprendizado que, mesmo mediante as problemáticas surgidas no decorrer deste - devido às greves e mudança de campo de estágio - ofereceu um leque de oportunidades para a apreciação e discussão acerca da presença da educação física na educação infantil apontando suas contribuições neste tempoespaço. 
A educação infantil foi reconhecida tardiamente em nossa sociedade, porém, atualmente tem ganhado espaço de preocupação ao ser reconhecida na Constituição de 1988 e com a produção de outros documentos oficiais que regulamentam sua organização (LDB/96 e RCNEI). A educação física aparece atrelada ao seu marco singular na condição de "não disciplina", mas como um tempo didático responsável por sistematizar os conhecimentos acerca do movimento e assim por consequência da cultura corporal.

Mediante a proposta de intervenção percebeu-se uma proficuidade quanto à percepção das crianças enquanto poéticas. Essa visão possibilitou construir um plano que se assegura às crianças possibilidades de serem autores do processo educacional. Uma vez que mediante os conteúdos propostos construímos juntamente com as crianças - no cotidiano - novas formas de fazer e brincar.

O brincar aparece como instrumento pedagógico e também como possível campo de entendimento das relações estabelecidas pelas crianças. São através das brincadeiras que percebemos os usos e consumos que as crianças fazem dessas, assim denotando suas manipulações secundárias, as bricolagens e operações próprias sobre esse fenômeno sociocultural.

Neste momento aparece o espaço da "não-aula" mediante a desconstrução da estrutura da aula segundo o molde escolarizante que por muito tempo foi pretendido na educação infantil - e hodiernamente ainda o é. Assim a organização de uma rotina flexível às necessidades e anseios das crianças mostra-se profícua na construção de um tempo didático comprometido com o trabalho educativo de excelência a ser prestado neste nível de ensino.

Essas considerações constituem-se como aproximações heurísticas dos achados durante nossa passagem pelos campos de estágio. Ainda estamos longe de perceber a criança em sua alteridade - na esfera empírica. Entretanto o compromisso da busca tem-se mostrado fiel aos objetivos de proporcionar uma educação que não esteja numa via unilateral, assim atendendo as crianças enquanto seres totais, únicos e indivisíveis, uma vez que as mesmas sendo formado sócio-históricoculturalmente, também são formadoras. 
The daily of early childhood education and physical education presence in the poetic of child be

\begin{abstract}
This study is the result of activities developed in Supervised Practices and aims to present the experiences obtained during the course of arguing that the presence of daily physical education in early childhood education in a Municipal Center of Childhood Education in the city of Cariacica/ES. The methodology was based on a qualitative setting in the implementation of nine interventions to a class of twenty children aged four years. The theoretical and methodological discussion was drawn by the heuristic character research was based on the concept of daily seeing children as poetic, producing knowledge and active subjects in the teaching-learning process.
\end{abstract}

Keywords: Child Rearing. Physical Education and Training. Early Intervention (Education).

Lo cotidiano de la educación infantil y la presencia de la educación física en la poética de ser niño

\title{
Resumen
}

Este estudio es resultado de las actividades desarrolladas en las prácticas supervisadas y tiene objetivo de presentar las experiencias obtenidas durante el curso de lo mismo argumentando de que la presencia de la educación física en el cotidiano de la educación infantil en el Centro Municipal de Educación Infantil del municipio de Cariacica/ES. La metodología utilizada se basó en la configuración de tipo cualitativo teniendo la configuración de la aplicación de nueve intervenciones a un grupo de veinte niños de cuatro años. La discusión teórica y metodológica fue elaborado por la investigación de carácter heurística y se basa en el concepto de lo cotidiano percibiendo los niños en cuanto poéticas, productoras del conocimiento y sujetos activos en el proceso enseño-aprendizaje.

Palabras clave: Crianza del Niño. Educación y Entrenamiento Físico. Intervención Precoz (Educación).

\section{Referências}

ANDRADE FILHO, N. F. Perspectiva Pedagógica da Educação Física para a Educação Infantil: provocações. In: GRUNENNWALDT, J. T. et al (Org.). Educação física, esporte e sociedade: temas emergentes. vol. 1. São Cristóvão: Universidade Federal de Sergipe, 2007, p. 2340 .

BERNARDES, E. L. Jogos e brincadeiras tradicionais: um passeio pela história. In: VI CONGRESSO LUSO-BRASILEIRO DE HISTÓRIA DA EDUCAÇÃO, 6., 2006, Uberlândia. Anais..., Uberlândia: 
COLUBHE, 2006. Disponível em: <http://www.faced.ufu.br/colubhe06/anais/arquivos/47ElizabethBernardes.pdf $>$. Acesso em 04 dez. 2010.

BRASIL. Referencial curricular nacional para a educação infantil. vol. 1. Brasília: MEC/SEF, 1998a.

BRASIL. Referencial curricular nacional para a educação infantil. vol. 2. Brasília: MEC/SEF, 1998b.

BRASIL. Referencial curricular nacional para a educação infantil. vol. 3. Brasília: MEC/SEF, 1998c.

CERTEAU, M. A invenção do cotidiano 1: Artes de fazer. Petrópolis, RJ: Vozes, 1994.

FOUCAULT, M. Vigiar e punir: nascimento da prisão. 38. ed. Petrópolis, RJ: Vozes, 2010.

FREIRE, P. Pedagogia da autonomia: saberes necessário a prática educativa. 24. ed. São Paulo: Paz e Terra, 1996.

OLIVEIRA, Z. M. R. Educação Infantil: fundamentos e métodos. 4. ed. São Paulo: Cortez, 2008.

SAYÃO, D. T. Infância, Prática de Ensino de Educação Física e Educação Infantil. In: VAZ, A. F.; SAYÃO, D. T.; PINTO, F. M (Org.). Educação do corpo e formação de professores: reflexões sobre a prática de ensino de educação física. Florianópolis: UFSC, 2002, p. 45-64.

SILVA, E. G.; BAUMEL, R. C. Corpo-movimento: desafios das linguagens infantis para a educação. In: CONGRESSO DE LEITURA DO BRASIL, 17., 2009, Campinas. Anais..., Campinas-SP: ALB, 2009. Disponível em: <http://www.alb.com.br/anais17/txtcompletos/sem14/COLE_3796.pdf $>$. Acesso em 22 Out. 2010.

SILVA, E. G.; SANT'AGOSTINO, L. H.F.; KUNZ, E. A semiótica peirciana e o se-movimentar infantil: semioses. In: CONGRESSO BRASILEIRO DE CIÊNCIAS DO ESPORTE e CONGRESSO INTERNACIONAL DE CIÊNCIAS DO ESPORTE, 15. [e] 2., 2007, Recife. Anais..., Recife-PE: CBCE, 2007. Disponível em: 
$<$ http://www.cbce.org.br/cd/resumos/113.pdf $>$. Acesso em 22 de out. 2010 .

Recebido em: 13/11/2011

Revisado em: 10/04/2012

Aprovado em: 21/06/2012

\section{Endereço para correspondência}

niltonpoletto@bol.com.br

Nilton Poletto Pimentel

Universidade Católica do Espírito Santo

Av Vitória, 950, Forte São João

Vitória-ES. CEP 29017- 950 